\title{
The problem-solving skills of the teachers in various branches
}

\author{
Veysel TEMEL \\ Karamanoglu Mehmetbey University, Physical Education and Sports High School, Karaman, Turkey. \\ Received 24 December 2014; Accepted 22 February, 2015
}

\begin{abstract}
The aim of this study was to determine the problem-solving skills of the teachers in various branches in Çat town of Erzurum Province in Turkey, using some variables. A total of 153 teachers (84 females, 69 males and age: 1.6536 \pm 0.72837 ) from different departments participated in the study. Problem Solving Inventory, developed by Heppner and Peterson (1982), was used to measure the problem solving skill level of the individual. For processing data, conventional statistical measures and methods were employed: Analysis of variance (ANOVA) test, tukey test, t-test, mean frequency distribution and standard deviation were computed. SPSS was used for analyzing of data. Results showed that the teachers had moderate problem-solving skills, According to course hours variables of the teachers entering, among impatient, thinking, avoidant, planned approach levels, mother occupation level between planned and thinking approach levels, the father's educational levels according to problem solving total scores and sport branches variable and among the thinking, self-confident, planned approach and problem solving total scores were statistically found meaningful difference $(p<.05)$.
\end{abstract}

Key words: Problem solving, teachers, teachers' skills.

\section{INTRODUCTION}

A teacher usually has to complete the following activities in teaching process: (1) explain the core knowledge of a problem; (2) show how to solve the problems with specific knowledge; (3) provide solutions and work examples of a problem; (4) give targeted feedback to students in the process of their trying to solve the problem; (5) recommend related activities based on students' cognitive state. Student model is the core element of ITS, based on which ITS is able to select the most suitable teaching strategies, provide related examples according to the needs of students, and replace human teachers to some extent (Shi et al., 2002).

Skill as an advanced cognitive ability can be understood as the ability of using concepts and rules to solve problem. It is difficult to be achieved by using traditional teaching methods, such as lectures, knowledge representation (Hwang et al., 2014). The learner should practice and strengthen the process continuously to complete the task. In teaching ICT, researchers gradually become aware of the importance of operational

E-mail: veyselltemel@gma il.com, veyseltemel@kmu.edu.tr. Tel: +905346661111, +90338226219.

Authors agree that this artic le remain pemanently open access under the terms of the Creative Commons Attribution License 4.0 Intemational License 
skills training and developing a variety of teaching aids systems and simulation tools, such as RCOS (Chernich et al., 1996), SOsim (Maia, 2003), in order to promote students' understanding of abstract concepts in computer courses and correct students' misconceptions. Some simulating teaching systems, such as MINIX (Herder et al., 2006; Nachos (Christopher et al., 1993) filter out the complexity of the real-life situation, so that students could understand the most basic concepts of knowledge and steps in a relatively simple context (Buendia and Cano, 2006). Web-based learning platform, such as WebCT, BlackBoard, was also used to assist the instruction, providing a wide range of learning resources. Based on the platform and resources, students were able to learn the contents of each module on demand, watching video lessons, reviewing the missing contents. To some extent, it can support students to carry out resource-based learning and achieve a better learning effect; but it still cannot support the skill acquisition in an effective way.

Problem was defined as an obstacle against available difficulties gathered by an individual to reach his target (Bingham, 1983). Keeneland described problem as the difference between the available and expected situation of something (Keeneland, 1999). According to Morgan, problem is described as the case of conflict when an individual encounters hindrance while reaching a target and finding it harder to reach the target with this hindrance; finding the best way to overcome the hindrance means solving the problem (Morgan, 1982). People face a lot of situations for solving problems in their daily lives. Problem solving involves reasoning and problem-overcoming is process that starts from the individual feeling the difficulties in reaching a target and the duration spent in finding a solution to it (Ülküer, 1988). This process aims to look for the ways to restore organism's inner balance and to get rid of the stress through obeying the rules and decreasing the hindrances. Therefore, problem solving is a comprehensive knowledge and skill which should be learnt and obtained and it should always be enhanced (Bingham, 1983; Sungur, 1992).

According to Erden (2005), giving students problem solving skills is one of the prior goals of all educational institutions. Especially in programs depending on progressive and reconstructive philosophical movement, improving problem solving skill is the main goal of education. People need to have this skill to adapt to social life and change, to be a successful and independent person.

To Bingham (1958), teachers are responsible for seeing that capacities in the surrounding can be changed into remarkable learning situations, and adding new elements into the situation. According to Hmelo (2004) and Watts (1994) teachers help students in learning the cognitive information they need for problem solving and cooperation.

Problem solving process starts with understanding the problem or gaining awareness, and continues with the stages of producing alternative strategies and applying by choosing amongst one of those alternatives. Lastly that chosen solution is needed to be confirmed In the following years. Tomas (1999) arranges the problem solving process in five stages:

$1^{\text {st }}$ Step: Define the problem

$2^{\text {nd }}$ Step: Collect information about source of the problem

$3^{\text {rd }}$ Step: Develop alternative solutions for the problem

$4^{\text {th }}$ Step: Choose the most suitable solution

$5^{\text {th }}$ Step: Apply the solution.

Rather than giving information to students about how to solve an encountered problem, teachers must bring solving skill for their own problems (Karplus, 1977). There are two main approaches in problem solving. Firstly, teachers configure the information actively in cooperation groups. Secondly, student and teacher roles have changed their form. Teacher is no longer the main source of the information. What is done in cooperation is the facilitator of learning. In the learning process for them to explore, the teacher guide to discover students' thoughts by asking open-ended questions and include them into the group process (Hmelo, 2004; Von Glasersfeld, 1991). In such atmosphere, students understand creative thinking and problem solving better, trust themselves more in creativec skills, get ready for using creative approaches more in solving professional problems and showing more creative approaches in daily life (Davis, 1980). To Duffy and Cunningham (2001) in problem solving process, students take more responsibility; become more independent and self-regulatory individuals.

\section{METHODS}

\section{Study universe and sample}

In this study, it was aimed to investigate the problem-solving skills of the teachers working in various branches, like math, physical education and sports, history, music and English, in terms of some of the variables. The study comprised a descriptive study. The result obtained from research was restricted with 153 teachers, the study group; 168 teachers from 310 working in the central schools depending on Ministry of Education in Cat town of Erzurum province in 2014-2015 academic year were reached; but the 15 survey was excluded from evaluation. There were a total of 84 women and 69 men (Age $(1.6536 \pm 0.72837)$ in 153 different branches ( Physical education and sports teachers, math teachers, history teachers, music teachers and english teachers).

\section{Data collection tool}

In the study, totally 153 teachers who were working in Cat town of Erzurum City in Turkey were given questionnaires. Problem Solving Inventory, developed by Heppner and Peterson (1982), was used to measure the problem solving skill level of the individual. The Turkish version of the problem Solving Inventory was realized by Şahin et al. (1993) and the personal information sheet of 14 questions was used. 
Table 1. Results of teachers related to $\bar{X}$ and Ss values of problem solving sub-dimensions and total point.

\begin{tabular}{lcccccc}
\hline $\begin{array}{l}\text { Sub-dimentions of } \\
\text { problem solving } \\
\text { inventory }\end{array}$ & $\mathbf{n}$ & $\bar{X}$ & Ss & Min. & Max. & $\begin{array}{c}\text { The max. \& min. } \\
\text { points in the } \\
\text { inventory }\end{array}$ \\
\hline Impetuous Approach & 153 & 33,5621 & 8,67000 &, 00 & 51,00 & $9-54$ \\
Considering Approach & 153 & 12,7516 & 4,94613 &, 00 & 25,00 & $5-30$ \\
Avaidant Approach & 153 & 16,3856 & 5,39752 &, 00 & 24,00 & $4-24$ \\
Evaluator Approach & 153 & 7,6601 & 3,13336 &, 00 & 16,00 & $3-18$ \\
Self-assured Approach & 153 & 20,7124 & 5,31343 &, 00 & 32,00 & $7-42$ \\
Planned Approach & 153 & 10,0850 & 4,02451 &, 00 & 23,00 & $4-24$ \\
Total Point & 153 & 101,1569 & 18,58838 &, 00 & 129,00 & $32-192$ \\
\hline
\end{tabular}

\section{Problem solving inventory}

This inventory scored between 1 and 6 is Likert type and measures one's own perceptions about one's problem solving skills. In the course of scoring $9^{\text {th }}, 22^{\text {nd }}$ and $29^{\text {th }}$ items were left aside from scoring. The $1^{\text {st }}, 2^{\text {nd }}, 3^{\text {rd }}, 11^{\text {th }}, 14^{\text {th }}, 15^{\text {th }}, 17^{\text {th }}, 21^{\text {st }}, 25^{\text {th }}, 30^{\text {th }}$ and $34^{\text {th }}$ items were scored in the inventory. The Problem Solving Inventory had six sub-dimensions which were: Impetuous Approach, Considering Approach, Avoidant Approach, Evaluator Approach, Self-assured Approach and Planned Approach. The least point was one and the utmost point was 6 in the answer key. At least, 32 and utmost 192 points could be taken in the whole Problem Solving Inventory. The total high score from the scale indicated that the individuals were perceived to be inadequate with regards to problem solving (Sahin et al., 1993).

\section{Data analysis and interpretation}

To evaluate the statistics, Statistical Package for the Social Sciences (SPSS) Windows version 21,00 package programme was used. Analysis of variance (ANOVA) test, tukey test ,t-test, mean frequency distribution and standard deviation were done.

On the first phrase of the research, demographic characteristics were analized. This study was done with the aim of presenting teachers' problem solving skill levels who were working in Cat town of Erzurum City in Turkey. The information obtained was interpreted as follows: In the first phase of the study, the demographic features of the participating teachers were determined. According to this, $84(54.9 \%)$ participants are females and $69(45.1 \%)$ are males. The age distribution of the teachers is $76(49.7 \%)$ of which we have between 20 and 25; 54(35.3\%), between 26 and 30; 23(15.0\%), between $31-35$ and over (Age $(1.6536 \pm 0.72837)$.. The marital status dispersion of the teachers is: $108(70.6 \%)$ are single, $35(70.6 \%)$ are married and $10(6,5 \%)$ are engaged. The education status dispersion of the participants is: $133(86.9 \%)$ of them have a master dgree and $20(13.1 \%)$ of them graduated from university. The year of the teachers working in a school is $130(85.0 \%)$ between 1 and 5 years, 23(15.0\%) between 6 and 10 years. When the teachers' residences were analyzed, teachers living in a metropole are $53(34.6 \%)$; city, $47(30.7 \%)$; town, $38(24.8 \%)$ and village and small town, $15(9.8 \%)$. Lesson hours of the teachers are; $17(11.1 \%)$ for below $15 \mathrm{~h}, 9(5.9 \%)$ for 15 and $18 \mathrm{~h}, 21(13.7 \%)$ for 19 and $22 \mathrm{~h}, 35(22.9)$ for 23 and $26 \mathrm{~h}$ and last one is $71(46.4 \%)$ for $27 \mathrm{~h}$ and above. The teachers' working schools are; $40(26.1 \%)$ in a primary school and $88(57.5 \%)$ in a secondary school, $25(16.3 \%)$ in a high school. The father's occupation dispersion of the participants is: $26(17.0 \%)$ of them are officials, $29(19.0 \%)$ of them are workers, $17(11.1 \%)$ of them are tradesman, $18(11.8 \%)$ of them are farmers and $63(41.2 \%)$ of them are retired. The mother's occupation dispersion of the participants is: $15(9.8 \%)$ of them are farmers, $22(14.4 \%)$ of them are retired and great majority of them are housewives, $11.1 \%(116)$. The father's education status dispersion of the participants is: $22(14.4 \%)$ are literates, $46(30.1 \%)$ are primary school leavers, $23(15.0 \%)$ are secondary school leavers, 42(27.5) are high school graduates and $20(13.1 \%)$ have four - year degree or two-year degree. The mother's education status dispersion of the participants is: $18(11.8 \%)$ are illiterates; $15(9.8 \%)$, literate; $75(49.0 \%)$ graduated from primary school; $23(15.0 \%)$, graduated from secondary school and $22(14.4 \%)$ graduated from high school. Doing sports rate of the teachers is: $60(39.2 \%)$ as yes and 93 $(60.8 \%)$ as no. The rate of the teachers doing individual sports is $32(20.9 \%)$ and team sports rate among the teachers is $28(18.3)$. On the second phase of the research, teachers' problem solving levels were determined.

\section{FINDINGS}

In the second part of the study, problem solving levels of teachers were tried to be determined.

In Table 1, problem solving sub-dimension and total points of teachers participating in the search were analyzed. At the end of this search, impetuous approach was found as $\bar{X}=33,5621$ ( $\min 9-\max 54)$ and avoidant approach was $\bar{X}=16,3856$ ( $\min 4-\max 24$ ). So it can be said that their points are mid-level. And also, considering approach was $\bar{X}=12,7516$ ( $\min 5-\max 30)$ and self-assured approach was $\bar{X}=20,7124(\min 7$ $\max 42$ ). So it can be said that their points are over medium level. Evaluator approach was $\bar{X}=7,6601$ ( $\mathrm{min}$ 3 - $\max 18)$ and planned approach was $\bar{X}=10,0850$ ( $\min 4-\max 24)$. So it can be said that the irpoints are over high level. Finally, problem solving total point was $\bar{X}=101,1569$. Problem solving total point was the minimum score of 32 and maximum score of 192 total point of the scale; where teachers' total point was $\bar{X}=101,1569$ in the problem solving inventory examined, it can be said that teachers participating in the research have mid-level problem solving skills. 
Table 2. The Oneway Anova-test results of problem solving inventory sub-dimensions of teachers related to the lesson hour variable.

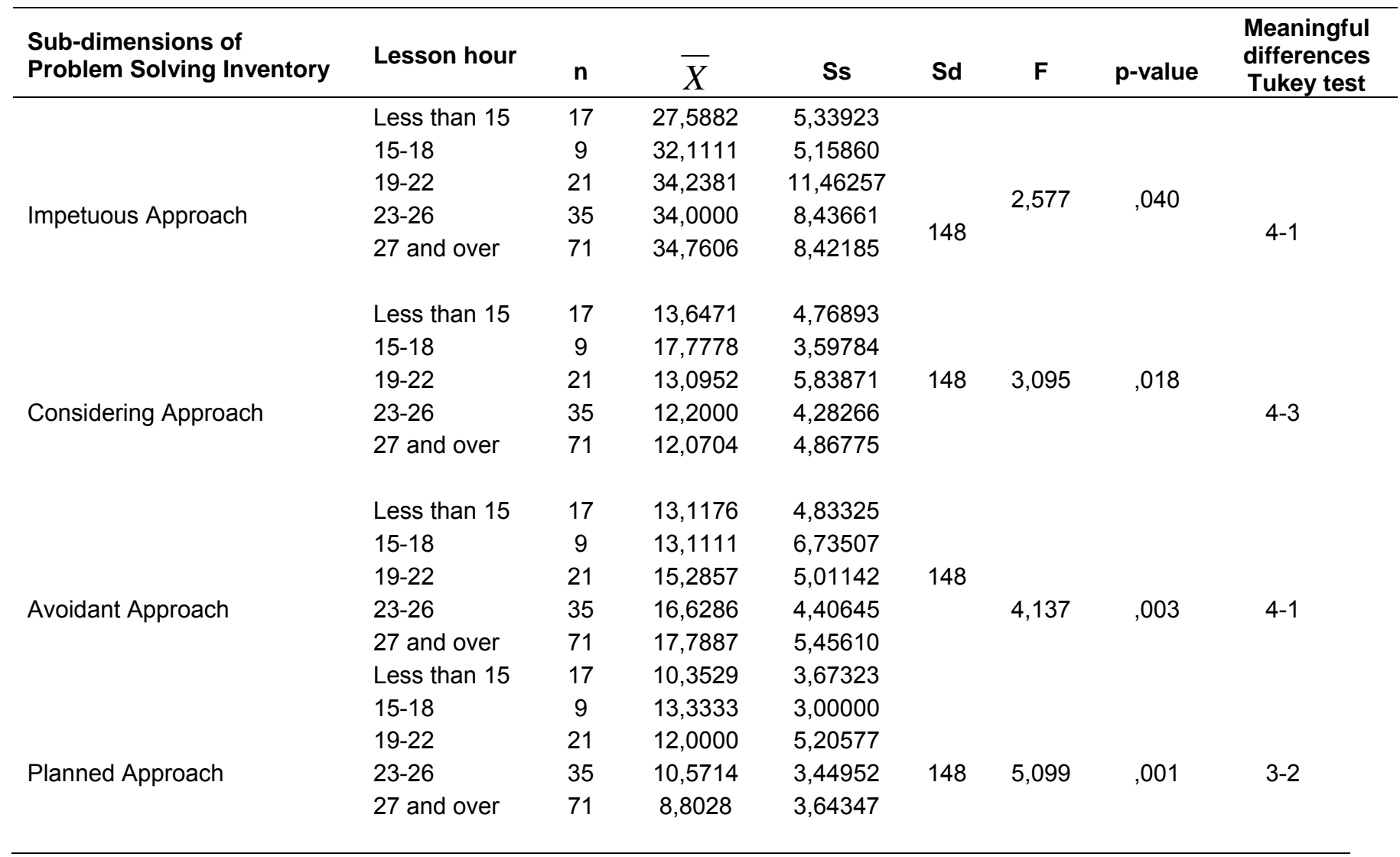

${ }^{*} \mathrm{p}<.05$

In Table 2, problem solving sub-dimension and one way anova-test results in relation to total points were analysed whether or not they differ according to "lesson hours variable when teachers enter class". At the end of the study, the teachers' points in impetuous approach are respectively $\bar{X}=27,5882$ for those who enter class less than $15 \mathrm{~h} ; \bar{X}=32,1111$ for between $15-18 \mathrm{~h}$, $\bar{X}=34,2381$ for between $19-22 \mathrm{~h}, \bar{X}=34,0000$ for between 23-26 $\mathrm{h}$ and $\bar{X}=34,7606$ for $27 \mathrm{~h}$ and over and a meaningful difference was found in terms of impetuous Approach points ( $F: 2,577 p<0,05)$.

The teachers' points in considering approach are respectively $\bar{X}=13,6471$ for those who enter class less than $15 \mathrm{~h} ; \bar{X}=17,7778$ for between $15-18 \mathrm{~h}$, $\bar{X}=13,0952$ for between $19-22 \mathrm{~h}, \bar{X}=12,2000$ for between 23-26 $\mathrm{h}$ and $\bar{X}=12,0704$ for $27 \mathrm{~h}$ and over and a meaningful difference was found in terms of considering approach points ( $F: 3,095 p<0,05)$.

The teachers' points in avoidant approach are respec- tively $\bar{X}=13,1176$ for those who enter class less than $15 \mathrm{~h} ; \bar{X}=13,1111$ for between $15-18 \mathrm{~h}, \bar{X}=15,2857$ for between 19-22 h, $\bar{X}=16,6286$ for between $23-26 \mathrm{~h}$ and $\bar{X}=17,7887$ for $27 \mathrm{~h}$ and over and a meaningful difference was found in terms of avoidant approach points ( $F: 4,137 p<0,05)$.

The teachers' points in planned approach approach are respectively $\bar{X}=10,3529$ for those who enter class less than $15 \mathrm{~h} ; \quad \bar{X}=13,3333$ for between $15-18 \mathrm{~h}$, $\bar{X}=12,0000$ for between $19-22 \mathrm{~h}, \bar{X}=10,5714$ for between $23-26 \mathrm{~h}$ and $\bar{X}=8,8028$ for $27 \mathrm{~h}$ and over and a meaningful difference was found in terms of planned approach points ( $F: 5,099 p<0,05$ ).

In Table 3, problem solving sub-dimension and oneway anova test results were analysed whether or not they differ according to 'teachers' mothers' jobs variable ". According to the table, the teachers' points in Considering Approach are respectively $\bar{X}=10,60000$ for 
Table 3. Teachers' mothers' jobs variable, problem solving skills related to the total score Oneway Anova test results.

\begin{tabular}{llccccccc}
\hline $\begin{array}{l}\text { Sub-dimensions of } \\
\text { problem solving } \\
\text { inventory }\end{array}$ & $\begin{array}{l}\text { Mother's } \\
\text { job }\end{array}$ & $\mathbf{n}$ & $\bar{X}$ & Ss & Sd & $\mathbf{F}$ & $\begin{array}{l}\text { Meaningful } \\
\text { p-value }\end{array}$ & $\begin{array}{c}\text { differences } \\
\text { Tukey test }\end{array}$ \\
\hline & Farmer & 15 & 10,6000 & 3,04256 & & & & \\
Considering & $\begin{array}{l}\text { Retired } \\
\text { Approach }\end{array}$ & 22 & 11,1818 & 4,88571 & 150 & 3,419 &, 035 & $1-3$ \\
& Housewife & 116 & 13,3276 & 5,04377 & & & & \\
\multirow{2}{*}{ Planned Approach } & Farmer & 15 & 9,0667 & 3,32666 & & & & \\
& Retired & 22 & 8,4091 & 2,90581 & 150 & 3,201 &, 044 & $2-3$ \\
\hline
\end{tabular}

${ }^{*} \mathrm{p}<.05$.

Table 4. Fathers' educational status variable of the teachers, problem solving skills related to the total score anova test results.

\begin{tabular}{llccccccc}
\hline $\begin{array}{l}\text { Sub-dimensions of } \\
\text { problem solving } \\
\text { inventory }\end{array}$ & $\begin{array}{l}\text { Fathers } \\
\text { educational } \\
\text { status status }\end{array}$ & $\mathbf{N}$ & $\bar{X}$ & Ss & Sd & $\mathbf{f}$ & $\begin{array}{l}\text { P-value } \\
\text { Peaningful } \\
\text { differences } \\
\text { tukey test }\end{array}$ \\
\hline & Literate & 22 & 91,4091 & 27,11116 & & & & \\
Total & Primary school & 46 & 100,3913 & 13,70398 & & & & \\
& Secondary school & 23 & 103,7391 & 13,35262 & & & & \\
& High school & 42 & 106,6905 & 13,22136 & 148 & 2,760 &, 030 & $1-4$ \\
\hline
\end{tabular}

${ }^{*} p<.05$.

being farmers, $\quad \bar{X}=11,1818$ for being retired and $\bar{X}=13,3276$ for being housewife and a meaningful difference was found in terms of Considering Approach points $(F: 3,419 p<0,05)$. According to the table, the teachers' points in planned approach are respectively $\bar{X}=9,0667$ for being farmers, $\bar{X}=8,4091$ for being retired and $\bar{X}=10,5345$ for being housewife and a meaningful difference was found in terms of Considering Approach points ( $F: 3,201 p<0,05)$.

In Table 4, problem solving total points and oneway anova test results were analysed whether or not they differ according to "fathers educational status variable". According to the table, the teachers' points in total points are respectively $\bar{X}=91,4091$ for literate fathers, $\bar{X}=$ 100,3913 for those who graduated from primary school, $\bar{X}=103,7391$ for those who graduated from secondary school, $\bar{X}=106,6905$ for those who graduated from high school and $\bar{X}=99,0500$ for those having Associate / Bachelor degree and a meaningful difference was found in terms of total points $(F: 2,760 p<0,05)$.

In Table 5, problem solving sub-dimension and t-test results were analysed whether or not they differ according to " sports branches which teachers do variable ". According to the table, while the teachers' points who do individual sports in Considering Approach are $\bar{X}=10,9063$, the teachers' points who do team sports in Considering Approach are $\bar{X}=14,3571$ and a meaningful difference was found in terms of Considering Approach points (t:0,144 $p<0,05)$.

While the teachers' points who do individual sports in Self-assured Approach are $\bar{X}=18,4063$, the teachers' points who do team sports in Self-assured Approach are $\bar{X}=21,5357$ and a meaningful difference was found in terms of Self-assured Approach points (t:0,771 $p<0,05$ ). While the teachers' point who do individual sports in planned Approach is $\bar{X}=8,0625$, the teachers' point who do team sports in planned Approach is $\bar{X}=11,2857$ and a meaningful difference was found in terms of planned Approach points (t:3,699 $p<0,05)$.

While the teachers' points who do individual sports in total point is $\bar{X}=93,1875$, the teachers' points who do team sports in total point is $\bar{X}=103,6071$ and a meaning- 
Table 5. Sports which teachers do variable, related to problem solving skills related to the sub-dimesions and total score t- test results.

\begin{tabular}{lllccccc}
\hline Sub-dimensions of problem solving inventory & Sports type & $\mathbf{n}$ & $\bar{X}$ & $\mathbf{S s}$ & $\mathbf{S d}$ & $\mathbf{t}$ & $\mathbf{p}$-Value \\
\hline Considering Approach & Individual Sports & 32 & 10,9063 & 5,40227 & & & \\
& Team Sports & 28 & 14,3571 & 5,16551 & 58 &, 144 &, 015 \\
& Individual Sports & 32 & 18,4063 & 6,15320 & & & \\
Self-assured Approach & Team Sports & 28 & 21,5357 & 5,16743 & 58 &, 771 &, 039 \\
& & & & & & & \\
Planned Approach & Individual Sports & 32 & 8,0625 & 3,14117 & & &, 001 \\
& Team Sports & 28 & 11,2857 & 4,12631 & 58 & 3,699 &, 01 \\
Total & Individual Sports & 32 & 93,1875 & 22,76448 & & &, 047 \\
\hline
\end{tabular}

${ }^{*} p<.05$

ful difference was found in terms of total points (t:0,326 $p<0,05)$.

\section{RESULT AND DISCUSSION}

This study was carried out to find out whether or not the ability of problem solving of the teachers differed according to the variables of gender, age, marital status, educational status, professional service year, the place where he/she lives the most, secondary education institutions they worked in, father's occupation, mother's occupation, parental education status, their active sportive level, lesson hours for a week and sports they do.

The results obtained in this study in order to identify problem-solving skills of the teachers were as follows; while problem solving skills of teachers participating in the study were detected in the medium level, it could be said that impetuous approach $(\bar{X}=33,5621$ ( $\min 9-\max$ 54)) and avoidant approach $(\bar{X}=16,3856(\min 4-\max$ 24)) were mid-level, considering approach ( $\bar{X}=12,7516$ $(\min 5-\max 30))$ and self-assured approach $(\bar{X}=20,7124(\min 7-\max 42))$ were over medium level, Evaluator approach $(\bar{X}=7,6601(\min 3-\max 18))$ and planned approach $(\bar{X}=10,0850(\min 4-\max 24))$ were over high level. On the other hand, A meaningful relationship was not found according to the teachers' gender, age, marital status, educational status, professional service year, the place where he/she lived the most, secondary education institutions they worked, mother's education status, father's occupation and their active sportive level. But, a meaningful relationship was found according to lesson hours for the week, mother's occupation, father's educational status and and sports they do actively.

Kir et al. (2013) carried a survey among the prospective teachers in the pedagogical competencey program. They found that the teachers in the pedagogical formation proramme had the ability of problem solving which was over mid-level and no significant difference was found according to the variables of the place they live the longest and gender; an important difference was found according to the variables of age, marital status, familşy income and the school and the faculty they graduated from.

At the end of Akpinar's study (2012), It is found that while there is a meaningful difference in sportsmen's marital status, education status, parents' education status, father's occupation, occupation in the game, the year of playing football professionally and the age of starting sport variables, there is no meaningful difference in playing team and age variables.

Taylan applied problem solving inventory to three groups by adapting Hepper's problem solving inventory, reliability and validity. The inventorty was applied to students who study at Ankara University, College of Science and at the end of the study a meaningful difference could not be encountered in gender and class variables but a meaningful difference was found when class and programme were taken together (Taylan, 1990).

At the end of Katkat's study on the comparison of gender and fields of teacher candidates' problem solving skills, a meaningful difference was not found in teacher candidates' gender and different class variables, but a meaningful difference was encountered in types of university enrollment and types of point variables (Katkat, 2001).

At the end of Tekin et al. (2007)'s study on examining students' problem solving skills who study at school of physical education and sport, meaningful differences were found in avoidant approach for female students, the way of considering, avoidant, evaluator, self-assured and 
planned approach for students who do sport.

\section{ACKNOWLEDGMENT}

The authors would like to thank Assistant Professor Vedat AYAN and Assistant Professor Selahattin AKPINAR, Physical education and sports, by helping in the data acquisition.

\section{Conflict of Interests}

The author has not declared any conflict of interests

\section{REFERENCES}

Akpinar S (2012). A study on the problem solving competence of elite female hockey players in terms of certain variables. Energy Education Science and Technology Part B: Social and Educational Studies, Volume (issue) 4(3): 1473-1482.

Bingham A (1958). Improving children's facility in problem solving. New York: Teachers College, Columbia University. The development of problem solving skills inchildren. Trans .: A. Ferhan Oğuzkan.

Bingham A (1983). Development of Problem Solving Ability in Children. Trans .: Dr. A. Ferhan Oğuzkan, 4th edition, Ministry of Education Publications, İstanbul, Türkiye.

Buendia F, Cano JC (2006). A generative and web-based learning architecture to teach operating systems in undergraduate courses. IEEE Transactions on Education, 49(4):464-473.

Chernich R, Jamieson B, Jones D (1996). RCOS: yet another teaching operating system. Proceedings of the 1st Australasian conference on computer science education, ACM, pp. 216-222

Christopher WA, Procter SJ, Anderson TE (1993). The Nachos instructional operating system. Proceedings of the USENIX Winter 1993 Conference Proceedings on USENIX Winter Conference Proceedings, USENIX Association, pp. 4-4.

Duffy T M, Cunningham DJ (2001). Constructivism: implications for the design and delivery of instruction. the handbook of research for educational communications and technology. The Association for Educational Communications and Technology http://www.aect.org/intranet/publications/edtech/07/ index.html [02.11.2014].

Davis G (1980). The teaching of Elementary Problem Solving in Engineering and Related Fields. (Edit. Lubkin, James, L.) American Society for Engineering Education. Washington. D.C.

Erden M (2005). Introduction to Teaching Profession. Istanbul: Epsilon publishing

Heppner PP, Peterson HC (1982). The development and implications of a personal problem-solving inventory. Journal of Counseling Psychology, 29:66-73.

Herder JN, Bos H, Gras B, Homburg P, Tanenbaum AS(2006). MINIX 3: a highly reliable, self-repairing operating system. ACM SIGOPS Operating Systems Review, 40 (3):80-89.

Hmelo S, Cindy E (2004). Problem-based learning: what and how do students learn? Educational Psychology Review. 16 (3):235- 266. September.

Hwang YH, Kuo SC, Chen BB, Ho IK (2014). Effects of an integrated concept mapping and web-based problem-solving approach on students' learning achievements, perceptions and cognitive loads. Computers \& Education, 71:77-86
Karplus R (1977). Science teaching and the development of reasoning. J. Res. Sci. Teaching. 14:2.

Katkat D (2001). Comparison of Prospective Teachers' Problem Solving Skills in terms of Gender and Fields. Unpublished Master's Thesis. Atatürk University, School of Social Sciences, Erzurum.

Keeneland S (1999). Solving Problems Essentials. How to Books Ltd. Oxford. UK.

Kir et al. (2013). "The examination of the problem-solving skills of the prospective teachers participating in the pedagogical competence program". Intl. J. Acad. Res. Part B; 5(6):31-36.

Maia MAG (2003). Sosim: Simulator for operating systems education.

Morgan CT (1982). Introduction to psychology. Trans.:Arıcı H. et al., Meteksan, Ankara-Turkey.

Sahin N, Şahin NH, Heppner PP (1993). Psychometric Properties of The Problem Solving Inventory in A Group of Turkish University Student. Cognit. Ther. Res. 17(3):379-385.

Shi H, Rodriguez O, Chen S, Shang Y (2002). Integrating adaptive and intelligent techniques into a web-based environment for active learning. Intelligent Systems: Technology and Applications, 4, pp. 229-260.

Sungur N (1992). Creative thinking, Acer Printing, Istanbul, Turkey.

Taylan S (1990). Application of Heppner's problem Solving Inventory, Reliability and Validity studies. Ankara University Institute of Socia Sciences, Unpublished Master Thesis, Ankara.

Tekin M, Taskin O, Kivrak AO (2007). Investigation of Problem Solving Skills of the Students studying at school of Physical Education and Sport in terms of different variables. J. Ulkumuz 4(7):57-66.

Tomas S (1999). Creative Problem-Solving: An Approach To Generating Ideas. Hospital Materiel Management Quarterly. Health \& Medical Complete, 20(4):33.

Ülküer NS(1988). How do children acquire problem solving skills? Lifelong Education, $\mathrm{n}=5$.

Von GE (1991). Questions and answers about radical constructivism. scope, sequence, and coordination of secondary school science. (ed. M. K. Pearsall.) The National Science Teachers Association. Vol. II: Relevant research (169 182). (Final Draft, August 1991).

Watts M (1994). Constructivism, Re-constructivism and Task-orientated Problem-solving. The Content of Science: A Constructivist Approach to its Teaching and Learning. ed. Peter J. Fensham, Richard F. Gunstone, Richard T. White. London-Waffngton D.C.: The Falmer Press: 39-59. 